\title{
The vanadate-tolerant yeast Hansenula polymorpha undergoes cellular reorganization during growth in, and recovery from, the presence of vanadate
}

\author{
Ilaria Mannazzu, Emanuela Guerra, Rosanna Strabbioli, Dario Pediconi \\ and Fabrizio Fatichenti
}

Author for correspondence: Ilaria Mannazzu. Tel: +3971 2204855. Fax: + 39712204858 .

e-mail: ilaria@popcsi.unian.it

Dipartimento di

Biotecnologie Agrarie ed Ambientali, Università di Ancona, Via Brecce Bianche, Ancona 60131 Italy

\begin{abstract}
When present at intracellular concentrations above micromolar, vanadate becomes toxic to most organisms. However, the yeast Hansenula polymorpha is able to grow on vanadate concentrations in the millimolar range, showing at the same time modifications in cellular ultrastructure and polyphosphate metabolism. Here, the development of the ultrastructural changes, and of vacuolar and secretory activities, during exponential growth on vanadate and upon a return to vanadate-free conditions was investigated. External invertase secretion was inhibited by vanadate, as shown by a decrease in external invertase activity, an intracellular accumulation of small vesicles and a cytoplasmic accumulation of internal invertase. An aberrant appearance of the cell wall and defects in cellular surface growth, possibly linked to defects in secretion, were also observed. However, inhibition of the secretory pathway was not complete since the activity of another secreted enzyme, exoglucanase, increased in the presence of vanadate. Growth on vanadate was also accompanied by an enhancement of vacuolar proteolysis, as indicated by an increase in carboxypeptidase $Y$ activity. However, these modifications were all reversible upon return to vanadate-free conditions, with the normalization process being complex and involving new and dramatic ultrastructural changes and activation of an autophagic mechanism. This mechanism is involved in the elimination/resorption of the observed vanadate-induced aberrant cell structures and/or sites involved in vanadate accumulation, a necessary prerequisite for restoration of conventional ultrastructure and metabolic functions.
\end{abstract}

Keywords: Hansenula polymorpha, vanadate, ultrastructure, secretion, vacuolar activity

\section{INTRODUCTION}

It has been reported that the addition of vanadate $\left(\mathrm{VO}_{4}^{3-}\right)$ to the whole-cell system, in which vanadate can be reduced to vanadyl $\left(\mathrm{VO}^{2+}\right)$, increases DNA synthesis (Smith, 1983), protein phosphorylation (Brown \& Gordon, 1984; Karlund, 1985), chloride transport (Hatch et al., 1983) and cAMP levels (Catalan et al., 1980), and has an insulin-mimetic effect (Crans et al., 1995). Furthermore, in vivo and in vitro studies have

Abbreviations: CPY, carboxypeptidase Y; ExG, exoglucanase; Exl, external invertase; TEM, transmission electron microscopy. shown an inhibitory effect of vanadate on $\mathrm{Na}^{+} / \mathrm{K}^{+}$and P-type ATPases (Cantley et al., 1978; Karlish et al., 1979; Wach \& Graber, 1991), RNases (Lindquist et al., 1973), protein-acid- and alkaline phosphatases (Foulkes et al., 1983), phosphofructokinase and adenylate kinase (Chasteen, 1984). However, the mechanisms by which vanadium exerts a toxic effect on living organisms are not completely understood. This could be due to the variety of possible intracellular targets of the metal and to the changes in chemical form and oxidation state that vanadium can undergo (for details see Willsky, 1990) both in the external environment and intracellularly.

Whilst little is known about the apparent stimulatory 
effect of vanadyl on metabolic processes, a mechanism of 'ionic mimicry' seems to be responsible for many of the effects of vanadate. Vanadate has structural and metabolic similarities with phosphate: it enters the cell through the phosphate transport system in erythrocytes (Cantley et al., 1978), Neurospora crassa (Bowman, 1983) and Saccharomyces cerevisiae (Willsky et al., 1984) and affects many metabolic circuits by competing with endogenous phosphate in enzymic- and receptormediated processes.

In the yeast $S$. cerevisiae a detoxifying mechanism that can work efficiently at low vanadate concentrations has been hypothesized. In this case, after entering the cell, vanadate is reduced to vanadyl and then excreted in this form. However, at higher concentrations, the rate of vanadate influx overtakes that of vanadate reduction. Consequently, vanadate accumulates intracellularly, leading to the formation of toxic high-molecular-mass vanadate compounds which stop growth (Willsky et al., 1984). S. cerevisiae vanadate-resistant mutants do not accumulate vanadate compounds intracellularly and exhibit several phenotypic modifications, such as plasma membrane and cell wall aberrations, underglycosylation of secreted invertase, sporulation defects and increased sensitivity to hygromycin and detergents (Ballou et al., 1991; Kanik-Ennulat et al., 1995). All the genes implicated in vanadate resistance isolated so far code for proteins involved in the organization and functioning of the Golgi apparatus and the secretory pathway. Different models have been hypothesized for this resistance. Ballou et al. (1991) proposed that any mutation of a vanadate-sensitive target site involved in protein sorting in the Golgi, or in vanadate uptake, secretion or detoxification, could be responsible for vanadate resistance. Kanik-Ennulat et al. (1995) suggested that vanadate resistance could arise from alterations in the secretory pathway, which would allow cells to dilute or excrete toxic vanadate molecules formed intracellularly. These authors hypothesized that either a proliferation of the Golgi apparatus or a modification of vesicle or membrane targeting at the level of the Golgi could be responsible for the decreased toxicity of vanadate and for the general plasma membrane and cell wall defects observed in the vanadate-resistant mutants.

In the vanadate-tolerant yeast Hansenula polymorpha, growth in the presence of vanadate induces changes in cellular ultrastructure and in polyphosphate metabolism, and the appearance of intracellular vanadyl; such effects could indicate the activation of a detoxifying mechanism (Mannazzu et al., 1997). To understand the role of the observed modifications in vanadate tolerance, we have investigated the development of ultrastructural changes and of vacuolar and secretory activities during exponential growth on vanadate and upon return to vanadate-free conditions.

\section{METHODS}

Growth conditions. $H$. polymorpha strain NCYC 495 was used. Media used were GYNB ( $2 \%$ glucose, $0.7 \%$ Difco Yeast Nitrogen Base without amino acids), VGYNB (GYNB plus
$50 \mathrm{mM}$ sodium orthovanadate), SYNB (2\% sucrose, $0.7 \%$ Difco Yeast Nitrogen Base without amino acids) and VSYNB (SYNB plus $50 \mathrm{mM}$ sodium orthovanadate), all at $\mathrm{pH} 5.8$. Sodium orthovanadate (Sigma) was added to the sterile medium from a filter-sterilized stock solution $(500 \mathrm{mM}$, $\mathrm{pH} 5 \cdot 8$ ). Unless otherwise stated, $1 \times 10^{6}$ cells $\mathrm{ml}^{-1}$ from overnight precultures in GYNB were used as inoculum. Cells were grown aerobically at $37^{\circ} \mathrm{C}$ in an orbital shaker $(240$ r.p.m.).

Growth assessment. For growth rate calculations, growth was followed by measuring the $\mathrm{OD}_{600}$ every $2 \mathrm{~h}$ (Cary $1 \mathrm{E}$ UVVis, Varian spectrophotometer) using the supernatant as blank. For experiments on sucrose utilization and recovery from vanadate, growth was measured by cell counting in a haemocytometer.

Recovery from vanadate. Cells grown to mid-exponential phase on VGYNB or GYNB were harvested by centrifugation, washed twice in water and reinoculated into GYNB to a final concentration of $2.5 \times 10^{7}$ cells $\mathrm{ml}^{-1}$. Samples for growth assessment and ultrastructural and enzymic analyses were taken immediately after transfer to GYNB (time zero) and after a further $30,60,120$ and $240 \mathrm{~min}$.

Ultrastructural analyses. Cells were harvested by centrifugation, washed three times in water and fixed in $1 \%$ potassium permanganate for $20 \mathrm{~min}$ at room temperature. Pellets were then dehydrated in a graded series of ethanol concentrations (15 min for each solution containing 25, 60, 80 and $95 \%$ ethanol), embedded in Epon Araldite overnight at room temperature and treated at $60^{\circ} \mathrm{C}$ for $24 \mathrm{~h}$. Ultrathin sections of the order of $50 \mathrm{~nm}$ in thickness were stained for $40 \mathrm{~s}$ in a solution of lead citrate and observed by transmission electron microscopy (TEM; Philips CM12 electron microscope operating at $80 \mathrm{kV}$ ). For the ultrastructural analyses, 20-60 cells for each sample were selected at random and photographed at a final magnification of $\times 40000$. Relative vacuolar volumes were estimated using a stereological method according to Weibel (1979). Vesicles were scored as electrondense disks or rings $35-45 \mathrm{~nm}$ in diameter. Vesicle counts were normalized for cell volume, which was calculated by measuring the area of the cell section (measured from the plasma membrane) and using a section thickness of $50 \mathrm{~nm}$.

Immunoelectron microscopy. Cell fixation was performed as described by Mulholland et al. (1994), modified as follows. A $20 \mathrm{ml}$ volume of a culture of cells growing exponentially

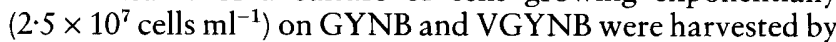
filtration through a $0.45 \mu \mathrm{m}$ pore-size nitrocellulose filter. Cells were dehydrated in a graded series of ethanol concentrations (5 min on ice for each solution containing 30, 80, 95 and $100 \%$ ethanol) and embedded in LR White embedding resin (Electron Microscopy Sciences), which was then polymerized. Ultrathin sections $(40-50 \mathrm{~nm})$ were mounted on nickel grids and immunolabelled according to the method of Preuss et al. (1991). Anti-invertase antibody (kindly provided by $\mathrm{Dr}$ Jesus Zueco, Universidad de Valencia, Spain) was diluted $1: 100$ in PBST $(140 \mathrm{mM} \mathrm{NaCl}, 3 \mathrm{mM} \mathrm{KCl}, 8 \mathrm{mM}$ $\mathrm{Na}_{2} \mathrm{HPO}_{4}, 1.5 \mathrm{mM} \mathrm{KH} \mathrm{PO}_{4}, 0.05 \%$ Tween 20) containing $0.5 \% \mathrm{BSA}$ and $0.5 \%$ ovalbumin. EM goat antirabbit IgG secondary antibody conjugated to $10 \mathrm{~nm}$ diameter gold particles (British BioCell International) was diluted 1:50 in PBST. Observations were made using a Philips CM12 electron microscope operating at $120 \mathrm{kV}$.

Enzymic assays. External invertase (ExI) activity was assayed on whole cells as described by Goldstein \& Lampen (1975), modified as follows. The enzymic and colorimetric reactions were carried out at $37^{\circ} \mathrm{C}$ for $10 \mathrm{~min}$ and $20 \mathrm{~min}$, respectively; 
the enzymic reaction was stopped by the addition of $0.3 \mathrm{ml}$ $0 \cdot 2 \mathrm{M} \mathrm{K}_{2} \mathrm{HPO}_{4} \mathrm{pH} \mathrm{10}$; the colorimetric reaction was stopped by the addition of $2 \mathrm{ml} 6 \mathrm{M} \mathrm{HCl}$. One unit $(\mathrm{U})$ corresponds to $1 \mu \mathrm{mol}$ glucose released $\mathrm{min}^{-1}$ and activity is expressed as $\mathrm{U}$ $(\mathrm{mg} \text { dry } \mathrm{wt})^{-1}$. Total invertase (external plus internal) was assayed on crude extracts as described above. Activity is expressed as $U$ (mg protein $)^{-1}$.

Exoglucanase (ExG) activity was determined on whole cells as described by Santos et al. (1979), modified as follows. The enzymic reaction was carried out in $0.25 \mathrm{ml}$ buffer containing $0.25 \% \quad p$-nitrophenyl- $\beta$-D-glucopyranoside as substrate, $50 \mathrm{mM}$ acetate buffer $\mathrm{pH} 5 \cdot 5,10 \mathrm{mM} \mathrm{NaN}_{3}, 0 \cdot 1 \%$ Triton X200 , and incubated at $37^{\circ} \mathrm{C}$ for $3 \mathrm{~h}$. The concentration of $p$ nitrophenol was measured by adding $2 \mathrm{ml}$ of $4 \% \mathrm{Na}_{2} \mathrm{CO}_{3}$ to $0.25 \mathrm{ml}$ of the reaction mixture. One unit (U) corresponds to 1 nmol $p$-nitrophenol released $\mathrm{min}^{-1}$ and activity is expressed as $\mathrm{U}$ (mg dry wt) $)^{-1}$.

Carboxypeptidase Y (CPY) activity was assayed on crude extracts according to a modification of the method of Aibara et al. (1971). Briefly, $0 \cdot 1 \mathrm{ml} 6 \mathrm{mM} \mathrm{N}$-benzoyl-L-tyrosine- $p$ nitroanilide (BTPNA; Sigma) in dimethylformamide was added to $0.4 \mathrm{ml} 0.1 \mathrm{M}$ Tris $/ \mathrm{HCl} \mathrm{pH} 7.6$ and $0.1 \mathrm{ml}$ crude extract at $37^{\circ} \mathrm{C}$. After $30 \mathrm{~min}, 1.5 \mathrm{ml} 1 \mathrm{mM} \mathrm{HgCl}$ was added to stop the reaction, followed by addition of $0 \cdot 2 \mathrm{ml} 20 \%$ SDS and $3 \mathrm{~min}$ incubation at $60^{\circ} \mathrm{C}$ to solubilize proteins. After $10 \mathrm{~min}$ at room temperature, the absorbance at $410 \mathrm{~nm}$ was determined (Cary 1E UV-Vis, Varian spectrophotometer). One unit $(\mathrm{U})$ corresponds to $1 \mu \mathrm{mol} p$-nitroaniline produced $\min ^{-1}$ (molar absorption coefficient of $p$-nitroaniline $=8800$ $\left.\mathrm{M}^{-1} \mathrm{~cm}^{-1}\right)$. Activity is expressed as $\mathrm{mU}$ (mg protein) ${ }^{-1}$.

Preparation of crude extracts. Between 0.5 and $1.0 \times 10^{9}$ cells were harvested by centrifugation, washed twice in water and resuspended in $0.2 \mathrm{ml} 0.1 \mathrm{M}$ Tris $/ \mathrm{HCl} \mathrm{pH} \mathrm{7.6}$. About 0.7 vol. glass beads (diam. $45 \mu \mathrm{m}$, Sigma) was added, and the cells were broken by eight cycles of $30 \mathrm{~s}$ vortexing interspersed with $30 \mathrm{~s}$ in ice. The supernatant was collected by $10 \mathrm{~min}$ centrifugation in a microcentrifuge. The protein concentration of the extracts was determined according to Bradford (1976), using BSA as standard.

\section{RESULTS}

\section{Growth on vanadate induces ultrastructural and physiological modifications}

Whilst we have indicated previously that there is a visible (in TEM) thickening of the cell wall and increase in the number of small cytoplasmic vesicles in $H$. polymorpha grown on VGYNB (Mannazzu et al., 1997), these studies have now been extended to demonstrate the level and significance of these effects (see Table 1). At the vanadate concentration used $(50 \mathrm{mM})$, causing a $2 \cdot 5$ fold increase in generation time, there was also a doubling in cell wall thickness. We also observed formation of cell aggregates during growth and modifications in the cell wall matrix, such that it appeared bilayered and displayed an increased resistance to lytic enzymes (data not shown). In a small fraction of cells $(4.9 \%)$ electron-dense bodies were observed embedded in the cell wall (as also illustrated in Fig. 3d; see below), which were surrounded by less electron-dense material that was not distinguishable from cell wall matrix. Their content was occasionally connected to, and could not be differentiated from, the dense peripheral cytoplasm.

Cytoplasmic vesicles of about $40 \mathrm{~nm}$ diameter were observed in both GYNB- and VGYNB-grown cells, but their number increased by $167 \%$ in the presence of vanadate (see Table 1). Since vanadate is known to cause an inhibition of secretory vesicle release (Lew \& Simon, 1991) and an accumulation of 30-50 nm cytoplasmic vesicles has been observed in $S$. cerevisiae sec mutants (Novick et al., 1980; Rambourg et al., 1994), we tested the ability of $H$. polymorpha to grow on sucrose (requiring invertase secretion) in the presence of vanadate (data not shown). After $48 \mathrm{~h}$ the cell concentration in VSYNB cultures was more than one order of magnitude lower than that of VGYNB cultures. This was due to the presence of vanadate as control cultures (on SYNB and GYNB) grew to equal extents. However, the difference was less marked after $72 \mathrm{~h}$ and disappeared after $120 \mathrm{~h}$, when VSYNB cultures reached the same stationary-phase cell concentration as VGYNB and control cultures. The observed behaviour seemed to indicate a partial inhibition of secretion by vanadate, which could have caused the observed increase in vesicle number when cells were grown on VGYNB. To test this hypothesis we measured the levels of two secreted enzymes, ExI and ExG, under the same culture conditions used for TEM analyses. Whilst total (external plus internal) invertase was not significatively different in GYNB- and VGYNB-grown cells (data not shown), we observed a $39 \%(P<0.001)$ inhibition of ExI activity under VGYNB growth conditions (Table 1). This

\section{Table 1. Vanadate induces ultrastructural and metabolic modifications in $H$. polymorpha}

TEM analyses and measurements of growth rates and enzymic activities were performed on NCYC 495 cells growing exponentially in GYNB (control) or VGYNB, as described in Methods. Data given are means \pm sE. ExI, external invertase; ExG, exoglucanase; $\mathrm{CPY}$, carboxypeptidase $\mathrm{Y}$.

\begin{tabular}{|c|c|c|c|c|c|c|c|}
\hline \multirow[t]{2}{*}{ Conditions } & \multirow{2}{*}{$\begin{array}{l}\text { Generation } \\
\text { time }\left(h^{-1}\right)^{*}\end{array}$} & \multirow{2}{*}{$\begin{array}{c}\text { Cell wall } \\
\text { thickness }(\mu \mathrm{m}) \dagger\end{array}$} & \multicolumn{2}{|c|}{ Small cytoplasmic vesicles $†$} & \multirow{2}{*}{$\begin{array}{c}\text { ExI activity } \\
{\left[\mathrm{U}(\mathrm{mg} \text { dry } w \mathrm{t})^{-1}\right] \ddagger}\end{array}$} & \multirow{2}{*}{$\begin{array}{c}\text { ExG activity } \\
{\left[\mathrm{U}(\mathrm{mg} \text { dry } w t)^{-1}\right]^{*}}\end{array}$} & \multirow{2}{*}{$\begin{array}{c}\text { CPY activity } \\
{\left[\mathrm{U}(\mathrm{mg} \text { protein })^{-1}\right]^{*}}\end{array}$} \\
\hline & & & Size $(\mathbf{n m})$ & No. $\left(\mu \mathrm{m}^{-3}\right)$ & & & \\
\hline & $1.413 \pm 0.033$ & 101 & $39 \cdot 40 \pm 1 \cdot 90$ & 54 & $0 \cdot 11$ & $0 \cdot 10$ & \\
\hline VGYNB & $4.793 \pm 0.318 \$$ & $0 \cdot 197 \pm 0.012 \$$ & $42 \cdot 10 \pm 1 \cdot 72$ & $145 \cdot 87 \pm 12 \cdot 62 \S$ & $0.070 \pm 0.002 \$$ & $0 \cdot 296 \pm 0.014 \$$ & $2 \cdot 873 \pm 0 \cdot 092 \$$ \\
\hline
\end{tabular}

$* n=3$. $\quad \dagger n=50 . \quad \ddagger n=14 . \quad$ S Significantly different from value for GYNB $(P<0 \cdot 001)$. 


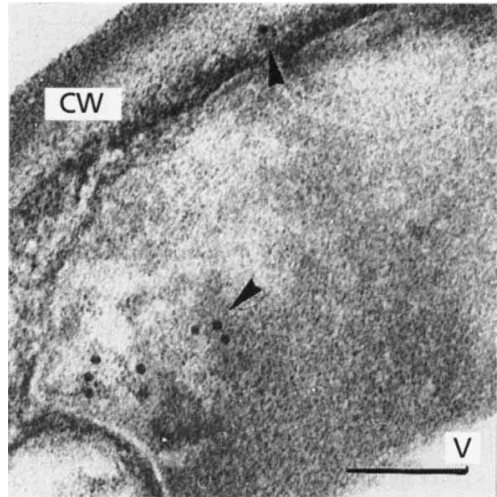

Fig. 1. Immunogold labelling of invertase in VGYNB-grown $H$. polymorpha cells. Arrowheads indicate $10 \mathrm{~nm}$ diameter gold particles. CW, cell wall; V, vacuole. Bar, $0.1 \mu \mathrm{m}$.

indicates that vanadate inhibits secretion, rather than overall production, of invertase and causes the accumulation of internal invertase. Also, by means of immunogold staining using an anti-invertase antibody, the localization of invertase was shown to be mainly cytoplasmic in VGYNB-grown cells (Fig. 1). The decrease in invertase secretion was accompanied by a $185 \%(P<0.001)$ increase in ExG activity in the presence of vanadate. These results indicated a divergence in the pathway to the cell surface for the two enzymes tested and a selective inhibitory effect of vanadate on invertase secretion.

A vanadate-induced doubling in vacuolar area has previously been observed in H. polymorpha (Mannazzu et al., 1997). To test whether the increased vacuolar area was accompanied by an increase in proteolytic activity, CPY activity was measured in cells growing exponentially with and without vanadate. As shown in Table $1, \mathrm{CPY}$ activity more than doubled in the presence of the metal. Furthermore, under the same growth conditions, the majority of vacuoles contained electron-dense material. In some cells $(5 \cdot 1 \%)$ vacuoles also showed fingerlike protrusions (see also below). This feature, previously observed in the yeast Pichia pastoris undergoing microautophagy under nitrogen starvation (Tuttle \& Dunn, 1995), was never encountered in GYNB-grown cells.

\section{Recovery from vanadate causes cellular rearrangements}

The modifications observed during exponential growth in vanadate-containing medium were followed upon return to vanadate-free conditions. To do this, cells grown to mid-exponential phase on VGYNB were thoroughly washed and reinoculated into GYNB. At the same time, a GYNB exponential culture was similarly washed, reinoculated into GYNB and used as a control. Whereas control cultures continued to grow at the same rate, cultures transferred from VGYNB to GYNB did not show any appreciable change in cell number for the

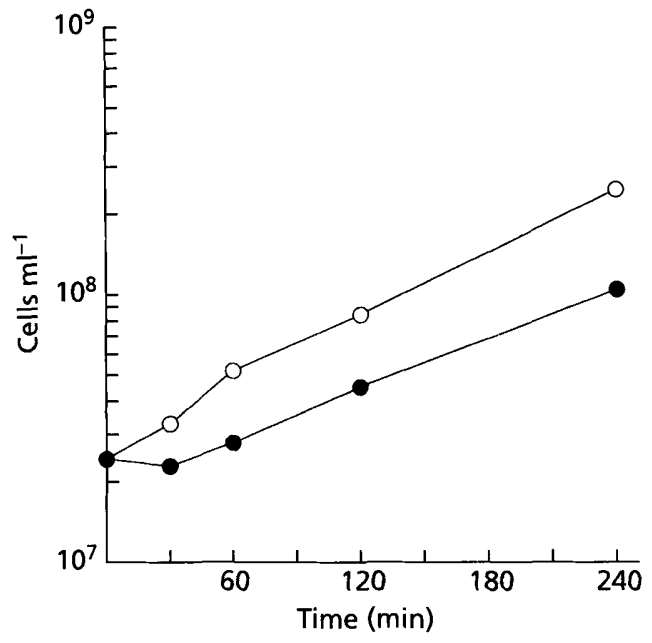

Fig. 2. $H$. polymorpha cells recovering from vanadate show a delay in growth resumption. Growth kinetics of NCYC 495 cultures grown to mid-exponential phase on GYNB $(O)$ or VGYNB (O) and reinoculated into GYNB at a concentration of $2.0-2.5 \times 10^{7}$ cells $\mathrm{ml}^{-1}$. Total cell numbers were counted immediately after the transfer (time zero) and after 30, 60, 120 and $240 \mathrm{~min}$. The data shown are representative of five independent experiments.

first $60 \mathrm{~min}$ (Fig. 2), during which time cells underwent new and dramatic ultrastructural modifications (Fig. 3). Whilst immediately after the reinoculation (time zero; Fig. 3b) cells showed the typical VGYNB ultrastructure, after $30 \mathrm{~min}$ the percentage of cells showing vacuoles with finger-like protrusions doubled (Fig. 4a, b). Most vacuoles also contained large amounts of electron-dense material (Fig. 3c). After 60 min (Figs 3d, 4c) the electrondense bodies sometimes observed in VGYNB-grown cells became much more evident, with an increase in the percentage of cells affected and in the number of bodies per cell (up to five). Furthermore, during this recovery phase, these electron-dense bodies could be found positioned in the cytoplasm as well as in the cell wall matrix. Whilst the appearance of both finger-like protrusions and electron-dense bodies associated with the cell wall matrix was only evident in relatively small percentages of cells under these conditions, the significance of these morphological features is supported by a consideration of their size and the thickness of the ultrathin sections $(50 \mathrm{~nm})$. Moreover, these features were never seen in control cells, or after the $240 \mathrm{~min}$ vanadate-recovery period (see below). Also, after 60 min, most vacuoles still contained large amounts of electron-dense material. At the same time, vacuolar volume showed a progressive $36 \%(P<0.001)$ reduction (Fig. 4d). After 120 and 240 min, growth was resumed at a rate comparable to that of the control, and the majority of cells had an appearance increasingly similar to that of cells growing in vanadate-free medium (compare Fig. 3a with Fig. 3e and f). The plasma membrane, which appears irregular during growth on vanadate (Mannazzu et al., 1997), showed a smoother contour and there was a decrease in cell wall thickness, 

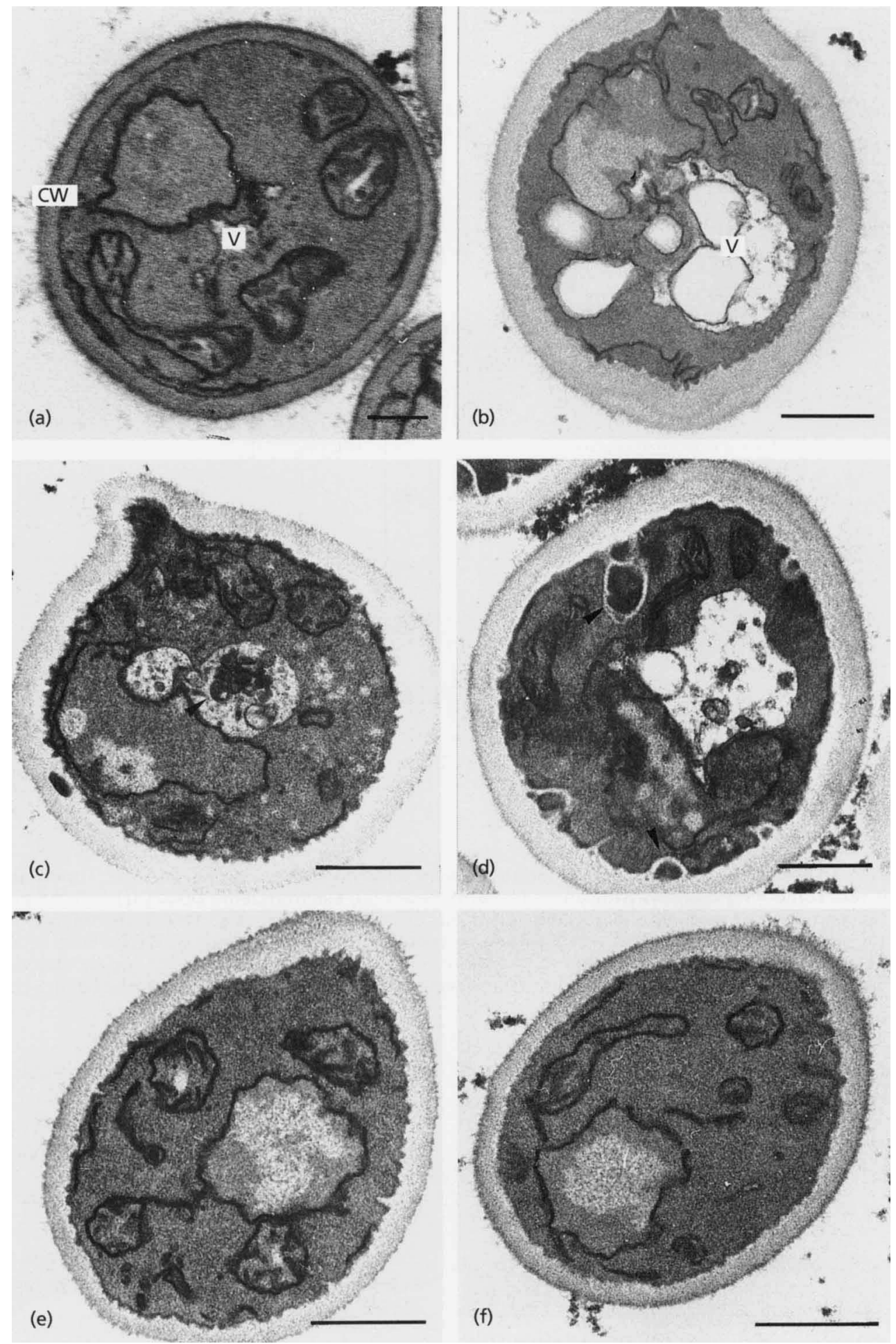

Fig. 3. Recovery of $H$. polymorpha from vanadate involves complex ultrastructural reorganization. NCYC 495 cells were grown to mid-exponential phase in VGYNB and reinoculated into GYNB at a concentration of $2.0-2.5 \times 10^{7}$ cells $\mathrm{ml}^{-1}$. Samples were taken immediately after the transfer (b) and after 30 (c), 60 (d), 120 (e) and 240 (f) min, fixed in potassium permanganate and visualized by TEM. A similar image of NCYC 495 cells growing exponentially in GYNB (no vanadate treatment) is shown in (a) for comparison. CW, cell wall; $\mathrm{V}$, vacuole; arrowheads indicate the electron-dense material inside the vacuoles and the dense structures embedded in the cell wall and in the cytoplasm. Bars, $0.5 \mu \mathrm{m}$. 

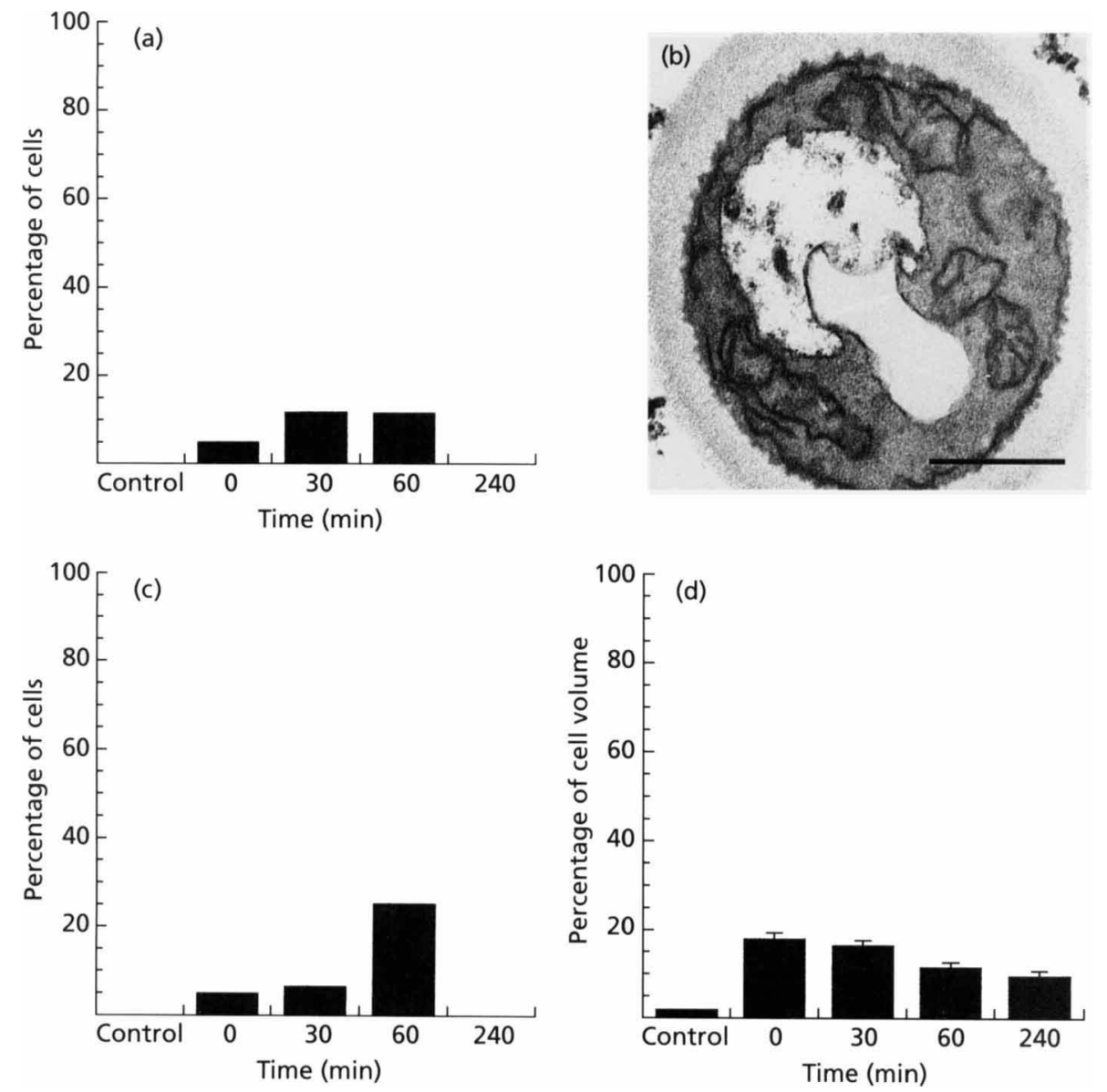

Fig. 4. Analyses of ultrastructural modifications during recovery of $H$. polymorpha from vanadate. Histograms show the percentage of cells containing vacuoles with finger-like protrusions (a), electron-dense bodies (c) and the percentage of cellular volume occupied by vacuoles (d) at the indicated times during recovery. One hundred per cent cellular volume $=1.85( \pm 0.12 \mathrm{SE}) \mu \mathrm{m}^{3}$. The control was a culture of cells growing exponentially in GYNB. Sixty cells selected at random were examined for each sample. Bars in (d) represent \pm SE. Data are representative of two independent recovery experiments. (b) TEM visualization of finger-like protrusion seen after $30 \mathrm{~min}$ of vanadate recovery. Bar, $0.5 \mu \mathrm{m}$.

which at $240 \mathrm{~min}$ was equal to $0 \cdot 109 \pm 0 \cdot 004 \mu \mathrm{m}$, not significatively different from that of the control (see Table 1 for comparison). The vacuolar volume further decreased, although it did not reach control values by 240 min (Fig. 4d).

After transfer from VGYNB to GYNB, there was also a delayed increase in ExI activity, which showed a 50\% recovery in the first $60 \mathrm{~min}$, thus approaching that of the control (Fig. 5a). This delayed recovery was also seen in the case of vesicle numbers (Fig. 5b), where there was an initial (30 min) increase, which was followed (after 60 $\mathrm{min}$ ) by a gradual return to control vesicle numbers (see also Table 1). ExG activity reached a peak $60 \mathrm{~min}$ after reinoculation into GYNB and progressively decreased at 120 and $240 \mathrm{~min}$ from reinoculation (Fig. 5c), indicating that the amount of secreted ExG increased during the delay in growth resumption (see Fig. 2) and declined concomitantly with growth rate recovery. This behaviour is somewhat surprising given that ExG activity has been directly related to growth rate in Candida albicans (Chambers \& Sullivan, 1993).
Cells transferred to vanadate-free medium also showed an initial further increase in CPY activity (Fig. 5d), which reached a peak 60 min after vanadate removal. After this time it progressively decreased, and was similar to that of the control after the 240 min recovery period. Interestingly, this higher CPY activity was concomitant with the increase in the percentage of cells containing vacuoles with large finger-like protrusions and the above-mentioned electron-dense bodies (See Fig. $4 a, c)$.

\section{DISCUSSION}

In this report we describe some aspects of the $H$. polymorpha response to the presence of high vanadate concentrations in the growth medium and demonstrate the reversible nature of these modifications. However, the processes leading to this normalization, activated upon the return to vanadate-free conditions, are very complex and involve profound ultrastructural and metabolic rearrangements which are particularly intense 

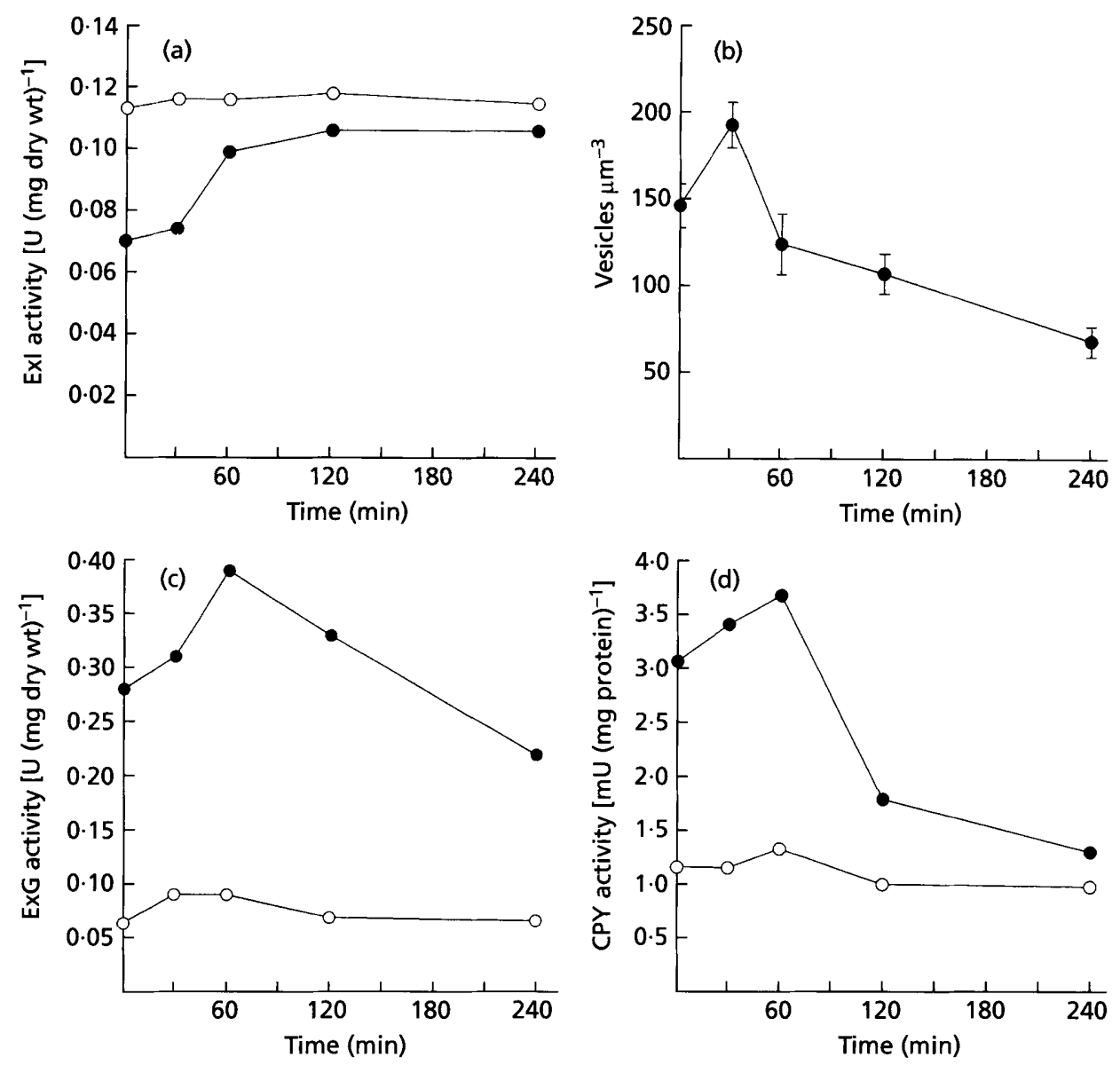

Fig. 5. $H$. polymorpha cells recovering from vanadate undergo changes in secretory and vacuolar proteolytic activities. (a) ExI activity, (b) vesicle number, (c) EXG activity and (d) CPY activity of cells transferred from GYNB (O; controls) and VGYNB (O) to GYNB. Cell samples were taken at the times indicated and assayed for enzymic activities as described in Methods. The data shown are representative of five independent experiments. Numbers of $40 \mathrm{~nm}$ vesicles were counted on TEM images of cells transferred from VGYNB to GYNB immediately after the transfer (time zero) and after 30, 60, 120 and $240 \mathrm{~min}$. Twenty cells selected at random were examined for each sample. Bars in (b) represent \pm SE.

during the first $60 \mathrm{~min}$ following the transfer from VGYNB to GYNB.

The decreased growth rate in VSYNB and the accumulation of $40 \mathrm{~nm}$ diameter vesicles, together with the mainly cytoplasmic localization of invertase and the inhibition of ExI activity, suggest a perturbation of secretion caused by vanadate in $H$. polymorpha. The decrease in the number of cytoplasmic vesicles and the increase in ExI activity observed upon return to vanadate-free conditions are consistent with this hypothesis. Similar behaviour has also been observed in $S$. cerevisae sec mutants, which at the non-permissive temperature do not export invertase and accumulate $50 \mathrm{~nm}$ secretory vesicles in the cytoplasm; upon the return to the permissive temperature, these secretory vesicles are released and ExI activity increases (Novick et al., 1980). In this study, under VGYNB culture conditions, decrease in ExI activity is accompanied by an increase in CPY and ExG activities. In the case of $\mathrm{CPY}$, the endoplasmic reticulum precursor p1CPY is converted to p2CPY in the Golgi and subsequently transported to the vacuole from a late Golgi compartment. In the vacuole, $\mathrm{p} 2 \mathrm{CPY}$ is processed to the active mature form of CPY (Mulholland et al., 1997). The increased CPY activity observed in vanadategrowing cells thus indicates that protein traffic from the endoplasmic reticulum to the Golgi, as well as through the late Golgi compartment, is fully active in the presence of vanadate. Furthermore, the increased ExG activity indicates an efficient delivery of this secreted protein from the late Golgi to the cell surface under VGYNB culture conditions. Study of post-Golgi vesicles of $S$. cerevisiae mutants blocked in Golgi to cell-surface transport led Harsay \& Bretscher (1995) to suggest that ExI and the major ExG normally secreted from the cell travel together from the trans-Golgi to the cell surface inside a population of secretory vesicles containing periplasmic enzymes and several plasma membrane permeases. However, an exoglucanasic activity was also found associated with a different secretory vesicle population. The vanadate-induced decrease in ExI 
activity, together with the increase in ExG activity, demonstrate that, in $H$. polymorpha, these two enzymes can be exported through different pathways from late Golgi to the cell surface. This could be due to protein sorting into different vesicles from the same compartment. It has also been hypothesized that different proteins might be transported inside vesicles budding from different compartments (Harsay \& Bretscher, 1995). This implies that a portion of secreted proteins could by-pass a post-Golgi intermediate compartment or a late-Golgi compartment and go to the plasma membrane through a different route. This hypothesis is supported by the results obtained by Ballou et al. (1991), who observed that some $S$. cerevisiae vanadate-resistant mutants show a defective glycosylation pattern of only a subset of secreted proteins, suggesting that different proteins may be processed through different glycosylation compartments. Therefore we can hypothesize the existence of a vanadate-sensitive target in the invertase route to the plasma membrane, which would not affect cellular components travelling within different secretory cargoes.

Cell wall modifications similar to those described in $H$. polymorpha growing exponentially on vanadate-containing medium have previously been observed in yeast. A heterogeneous and bilayered cell wall has been described in S. cerevisiae spe-1 mutants, with an altered ratio between glucans and mannoproteins, and the consequent accumulation of new mannoprotein molecules on the outer cell wall (Miret et al., 1992). Also, examination of S. cerevisiae sla 2 and act 1-1 mutant cells has revealed aberrant morphology of the cell wall and septum due to defects in the actin cytoskeleton, similar to that observed in H. polymorpha (Mulholland et al., 1997). A clumpy phenotype and an increased resistance to lytic enzymes have also been reported in $S$. cerevisiae vanadate-resistant mutants with altered secretion (Ballou et al., 1991; Kanik-Ennulat et al., 1995). Intriguingly, the metal-resistance of these mutants seems to arise from mutations that lead to different glycosylation phenotypes, and is inversely correlated to the extent of outer-chain elongation. Therefore, the aberrant appearance of the cell wall and the defects in cellular surface growth caused by vanadate in $H$. polymorpha could be linked to defects in secretion affecting the cell wall and plasma membrane architecture. To this extent the kinetics of ExG activity during growth on, and recovery from, vanadate is quite suggestive. Although the role of ExG is not fully understood, this enzyme is thought to be involved in cell wall metabolism and in the rearrangement of wall glucan (Sullivan et al., 1991). This increased secretion of ExG during VGYNB culture conditions could thus be due to the need to soften the rigid cell wall, thus allowing the insertion of new wall material. The further increase in ExG activity during the first $60 \mathrm{~min}$ of recovery, concomitant with the peak in CPY activity and with the increase in electron-dense structures, would permit this observed general reorganization of the cell wall components.
Another metabolic process strongly influenced by vanadate in $H$. polymorpha is vacuolar proteolytic activity, which doubled in VGYNB and initially continued to increase upon the return to vanadate-free medium, reaching a peak $60 \mathrm{~min}$ after the transfer. These higher levels of CPY activity were associated with the presence of electron-dense material inside the vacuoles and with a doubling in the appearance of vacuolar finger-like protrusions. This feature, previously observed in $P$. pastoris cells undergoing microautophagy, was initially accompanied by a significant reduction of vacuolar volume. Thus, the involvement of CPY in the degradation of proteins and peptides following adaptation to changing or limiting nutritional conditions, together with the observed ultrastructural modifications, suggest the activation of an autophagic mechanism. Autophagy has been described in S. cerevisiae cells which, under nutrient depletion, degrade part of their cytoplasm to supply required nutrients (Takeshige et al., 1992), and the vacuole has been shown to be an important site for the degradation of cytosolic components during nutrient stress in the methylotrophic yeast $P$. pastoris (Tuttle $\&$ Dunn, 1995). As the presence of vanadate in the growth medium could inhibit nutrient utilization, such inhibition could in part be responsible for the low growth rate observed in VGYNB and cause the activation of an autophagic mechanism. Upon transfer to vanadate-free medium, the cells would continue to experience this inhibition (as shown by the delay in the resumption of growth) due to the presence of vanadate or other forms of the metal ion complexed with the cell wall polymers and/or within the cell, as has already been seen in $H$. polymorpha (Zoroddu et al., 1991). This thus implies that, to resume normal growth, cells must undergo a process of elimination of these vanadium-containing compounds. Also, the elimination/resorption of cell wall or plasma membrane that has been incorrectly assembled during exponential growth on VGYNB may be necessary for growth resumption. Thus, a certain degree of autophagy would be induced by vanadatedependent inhibition of nutrient utilization, whilst the dramatic ultrastructural modifications observed upon recovery from vanadate would be part of the process of elimination/resorption of aberrant cellular structures and/or sites involved in vanadate accumulation. Therefore, vacuoles are involved not only in vanadate detoxification during growth on VGYNB (Mannazzu et al., 1997), but also in the normalization of ultrastructure and metabolic functions during recovery from vanadate.

\section{ACKNOWLEDGEMENTS}

We would like to thank Dr Chris Berrie for critical appraisal of the manuscript and Dr Jesus Zueco for providing the antiinvertase antibody.

\section{REFERENCES}

Aibara, S., Hayashi, R. \& Hata, T. (1971). Physical and chemical properties of yeast proteinase. Agric Biol Chem 35, 658-666.

Ballou, L., Hitzeman, R. A., Lewis, M. S. \& Ballou, C. E. (1991). 
Vanadate-resistant yeast mutants are defective in protein glycosylation. Proc Natl Acad Sci USA 88, 3209-3212.

Bowman, B. J. (1983). Vanadate uptake in Neurospora crassa occurs via phosphate transport system II. J Bacteriol 153, 286-291.

Bradford, M. M. (1976). A rapid and sensitive method for the quantitation of microgram quantities of protein utilizing the principle of protein-dye binding. Anal Biochem 72, 248-254.

Brown, D. \& Gordon, J. (1984). The stimulation of pp60v-src kinase activity by vanadate in intact cells accompanies a new phosphorylation state of the enzyme. J Biol Chem 259, 9580-9586.

Cantley, L. C., Resh, M. D. \& Guidotti, G. (1978). Vanadate inhibits the red cell $(\mathrm{Na}, \mathrm{K})$ ATPase from the cytoplasmic side. Nature 272, 552-554.

Catalan, R. E., Martinez, A. M. \& Aragones, M. D. (1980). Effects of vanadate on the cyclic AMP-protein kinase system in rat liver. Biochem Biophys Res Commun 96, 672-677.

Chambers, R. S. \& Sullivan, P.A. (1993). Expression of the exoglucanase gene in yeast and hyphal forms of Candida albicans. FEMS Microbiol Lett 111, 63-68.

Chasteen, N. D. (1984). The biochemistry of vanadium. Struct Bonding 53, 104-138.

Crans, D. C., Mahroof-Tahir, M. \& Keramidas, A. D. (1995). Vanadium chemistry and biochemistry of relevance for use of vanadium compounds as antidiabetic agents. Mol Cell Biochem $153,17-24$.

Foulkes, J. G., Erikson, E. \& Erikson, R. (1983). Separation of multiple phosphotyrosyl- and phosphoserosyl-protein phosphatases from chicken brain. J Biol Chem 258, 431-438.

Goldstein, A. \& Lampen, J. O. (1975). $\beta$-D-Fructofuranoside fructohydrolase from yeast. Methods Enzymol 42, 505-511.

Harsay, E. \& Bretscher, A. (1995). Parallel secretory pathways to the cell surface in yeast. J Cell Biol 131, 297-310.

Hatch, M., Freel, R. W., Goldner, A. W. \& Earnest, D. L. (1983). Vanadium ion stimulation of chloride secretion by rabbit colonic epithelium. Biochim Bibphys Acta 732, 699-704.

Kanik-Ennulat, C., Montalvo, E. \& Neff, N. (1995). Sodium orthovanadate-resistant mutants of Saccharomyces cerevisiae show defects in Golgi-mediated protein glycosylation, sporulation and detergent resistance. Genetics 140, 933-943.

Karlish, S. J. D., Beaugé, L. A. \& Glynn, I. M. (1979). Vanadate inhibits $\left(\mathrm{Na}^{+}+\mathrm{K}^{+}\right)$ATPase by blocking a conformational change of the unphosphorylated form. Nature 282, 333-335.

Karlund, J. (1985). Transformation of cells by an inhibitor of phosphatases acting on phosphotyrosine proteins. Cell 41, 707-717.

Lew, D. J. \& Simon, S. M. (1991). Characterization of constitutive exocytosis in the yeast Saccharomyces cerevisiae. J Membr Biol 123, 261-268.

Lindquist, R. N., Lynn, J. L. \& Lienhard, G. E. (1973). Possible transition-state analogs for ribonuclease. The complexes of uridine with oxovanadium (IV) ion and vanadium (V) ion. J Am Chem Soc 95, 8762-8768.

Mannazzu, I., Guerra, E., Strabbioli, R., Masia, A., Maestrale, G. B., Zoroddu, M. A. \& Fatichenti, F. (1997). Vanadium affects vacuolation and phosphate metabolism in Hansenula polymorpha. FEMS Microbiol Lett 147, 23-28.
Miret, J. J., Solari, A. J., Barderi, A. P. \& Goldemberg, S. H. (1992). Polyamines and cell wall organization in Saccharomyces cerevisiae. Yeast 8, 1033-1041.

Mulholland, J., Preuss, D., Moon, A., Wong, A., Drubin, D. \& Botstein, D. (1994). Ultrastructure of the yeast actin cytoskeleton and its association with the plasma membrane. J Cell Biol 125, 381-391.

Mulholland, J., Wesp, A., Riezman, H. \& Botstein, D. (1997). Yeast actin cytoskeleton mutants accumulate a new class of Golgiderived secretory vesicles. Mol Biol Cell 8, 1481-1499.

Novick, P., Field, C. \& Schekman, R. (1980). Identification of 23 complementation groups required for post-translational events in the yeast secretory pathway. Cell 21, 205-215.

Preuss, D., Mulholland, J., Kaiser, C. A., Orlean, P., Albright, C., Rose, M. D., Robbins, P. W. \& Botstein, D. (1991). Structure of the yeast endoplasmic reticulum: localization of ER proteins using immunofluorescence and immunoelectron microscopy. Yeast 7 , 891-911.

Rambourg, A., Clermont, Y., Jackson, C. L. \& Kepes, F. (1994). Ultrastructural modifications of vesicular and Golgi element in the Saccharomyces cerevisiae sec 21 mutant at permissive and non-permissive temperatures. Anat Rec 240, 32-41.

Santos, T., Del Rey, F., Conde, J., Villanueva, J. R. \& Nombela, C. (1979). Saccharomyces cerevisiae mutants defective in exo-1,3- $\beta$ glucanase production. J Bacteriol 139, 333-338.

Smith, J. (1983). Vanadium ions stimulate DNA synthesis in Swiss mouse 3T3 and 3T6 cells. Proc Natl Acad Sci USA 80, 6162-6166.

Sullivan, P. A., Emerson, G. W., Broughton, M. J. \& Stubbs, H. J. (1991). Transglucosylation catalysed by the exo- $\beta$-glucanase of Candida albicans. In Candida and Candidamycosis, pp. 35-38. Edited by E. Tumbay, H. P. R. Seeliger \& O. Ang. New York: Plenum.

Takeshige, K., Baba, M., Tsuboi, S., Noda, T. \& Oshumi, Y. (1992). Autophagy in yeast demonstrated with proteinase-deficient mutants and condition for its induction. J Cell Biol 119, 301-311.

Tuttle, D. L. \& Dunn, W. A., Jr (1995). Divergent modes of autophagy in the methylotrophic yeast Pichia pastoris. J Cell Sci $108,25-35$

Wach, A. \& Graber, P. (1991). The plasma membrane $\mathrm{H}^{+}$-ATPase from yeast. Effects of $\mathrm{pH}$, vanadate and erythrosine $\mathrm{B}$ on ATP hydrolysis and ATP binding. Eur J Biochem 201, 91-97.

Weibel, E. R. (1979). Stereological Methods: Practical Methods for Biological Morphometry, vol. 1. London: Academic Press.

Willsky, G. R. (1990). Vanadium in the biosphere. In Vanadium in Biological Systems, pp. 1-24. Edited by N. D. Chasteen. Dordrecht: Kluwer.

Willsky, G. R., White, D. A. \& McCabe, B. C. (1984). Metabolism of added orthovanadate to vanadyl and high-molecular-weight vanadate by Saccharomyces cerevisiae. J Biol Chem 21, 13273-13281.

Zoroddu, M. A., Bonomo, R. P., Di Bilio, A. J., Berardi, E. \& Meloni, M. G. (1991). EPR study on vanadyl and vanadate ion retention by a thermotolerant yeast. J Inorg Biochem 43, 731-738.

Received 2 March 1998; revised 7 May 1998; accepted 11 May 1998 